\title{
PROGRESSIVE SUPRANUCLEAR PALSY - LIKE SYNDROME INDUCED BY AMIODARONE AND FLUNARIZINE
}

\author{
James Pitágoras de Mattos', Denise Hack Nicaretta², Ana Lucia Zuma de Rosso'
}

Progressive supranuclear palsy (PSP) is a taupathy of unknown etiology, representing $7.5 \%$ of all cases of Parkinsonism and $50 \%$ of atypical Parkinsonism ${ }^{1,2}$. It was first described as a clinicopathological entity by Steele, Richardson and Olszewski in 1964. Clinically, PSP must be considered in any levodopa-unresponsive parkinsonian patient at middle-to-late age with progressive unexplained prominent postural instability with falls and supranuclear vertical gaze palsy ${ }^{1,2}$. The latter is characterized by limitation of upward, downward or lateral gaze, mainly downward. Other features are also important, such as: astonished face, retrocollis, lid freezing, monotonal speech, disartria, dysphagia, dementia and sloppy eaters ${ }^{1,2}$.

We report a patient with signs and symptoms suggestive of PSP who markedly improve six months after discontinuation of amiodarone and flunarizine.

\section{CASE}

A 74-year-old Caucasian woman presented rapid progression of an akinetic-rigid syndrome, with frequent falls, and became wheelchair-bound after only four months. At the age of 77 she was first seen by one of the authors (JPM). At that time her medications were levothyroxin ( $50 \mathrm{mcg} /$ day), captopril $(75 \mathrm{mg} /$ day), trimetadizine ( $60 \mathrm{mg} /$ day), levodopa + benserazide (600 $+150 \mathrm{mg} /$ day), biperiden (4 mg/day) and amantadine (200 mg/ day). She has a past medical history of hypothyroidism, essential hypertension, ventricular tachycardia with low cardiac output and dizziness. She has taken amiodarone $400 \mathrm{mg} /$ day and flunarizine $10 \mathrm{mg} /$ day since the age of 73 which had been discontinued a month before her first visit. On neurological examination, she was unable to stand or walk without assistance, and she had chin tremor, severe symmetric limb bradikinesia, axial rigidity, dysarthria and marked dysphagia. There were no pyramidal or cerebellar signs, or autonomic failure. Eye movements were normal and vertical gaze was preserved as were cognitive functions. The MRI showed moderate cortical and subcortical atrophy and ventricular enlargement. At that time biperiden and amantadine were discontinued, and pramipexole and tolcapone were titrated up to $3 \mathrm{mg} /$ day and $300 \mathrm{mg} /$ day, respectively. She underwent a percutaneous endoscopic gastrostomy (PEG) after an episode of aspiration pneumonia. In spite of adequate doses of antiparkinsonian medication, there was no improvement in three months. In fact, there was further deterioration of her neurological condition with the presence of retrocollis, vertical and lateral gaze palsy, lid opening apraxia (lid freezing) and cognitive decline. All these features were suggestive of PSP. Pramipexole was discontinued due to side effects (edema and somnolence), and memantine was added up to $20 \mathrm{mg} /$ day. After a few weeks she gradually improved, which was initially attributed to the memantine. After a five month interval with no news, surprisingly she reappeared with dramatic improvement in all her neurological features. She was able to walk without assistance, with slight postural instability. Mild asymmetric rigidity and bradikinesia were more prominent on the left. There was marked improvement of the retrocollis, lid freezing, gaze palsy and cognitive functions. The dysphagia was so mild that she had gained weight and the PEG has been removed. Ten months after the discontinuation of amiodarone and flunarizine, the patient had only mild parkinsonian signs on the left and did not require assistance for her activities of daily living. The levodopa, tolcapone and memantine were gradually discontinued. By the age of 79, she was free of parkinsonian symptoms.

\section{DISCUSSION}

Neurological features mimicking PSP have been described recently in the literature, secondary to other diseases or drugs, being known as PSP-like syndrome. Other diseases which can cause this include difuse subcortical cerebrovascular disease, cerebral Whipple's disease, and cerebral amyloid angiopathy, and, in a young patient, neurometabolic storage disorders, particularly Niemann-Pick disease type $C^{4,5}$. Drug-induced PSP features were only described in 1996 in a patient who had taken haloperidol, chlorpromazine and lithium, and in 2004, in another patient caused by clebopride 6 .

In the present case, our first impression was not of Par-

\section{PARALISIA SUPRANUCLEAR PROGRESSIVA SÍNDROME SIMILE INDUZIDA POR AMIODARONA E FLUNARIZINA}

'Hospital Universitário Clementino Fraga Filho, Serviço de Neurologia Prof. Sergio Novis, Setor de Distúrbios do Movimento, Universidade Federal do Rio de Janeiro, Rio de Janeiro RJ, Brasil; ${ }^{2}$ Santa Casa de Misericórdia do Rio de Janeiro, Serviço de Neurologia Prof. Sergio Novis, Setor de Distúrbios do Movimento, 24a e 25a Enfermarias, Rio de Janeiro RJ, Brasil.

Received 31 March 2009, received in final form 8 July 2009. Accepted 31 Juy 2009.

Dr. James Pitágoras de Mattos - Rua Santa Clara 50 / 702 - 22041-012 Rio de Janeiro RJ - Brasil. E-mail: jvmpmattos@globo.com.br 
kinson's disease because of the rapid onset of a symmetrical akinetic-rigid syndrome which rendered our patient wheelchair-bound after only four months, and the poor response to levodopa.

Clinical diagnosis of PSP only became evident two months after her first visit, with the onset of upward, downward and lateral gaze palsy, lid opening apraxia (lid freezing), retrocollis, dysarthria, marked dysphagia and cognitive decline. It is interesting that she continued to deteriorate even after the amiodarone and flunarizine were discontinued three months earlier. After three months of the clinical deterioration, surprisingly, she noticed a gradual neurological improvement. At this time, drug-induced parkinsonism was thought to be likely, caused by amiodarone or flunarizine or the synergic effect of both drugs.

The relationship between drugs and movement disorders is well established in the literature, specially with parkinsonism ${ }^{7}$. In 1984, Melo e Souza described the onset of parkinsonism due to cinarizine and flunarizine ${ }^{8}$. The mechanism of action of these calcium channel blockers on the CNS is not completely understood. It may inhibit proton pumping and dopamine uptake in storage vesicles, as well as block the dopamine D2 receptor in vivo. These mechanisms may be the cause of drug-induced parkinsonism 910 . The signs and symptoms can occur days, weeks or even months after the initiating these drugs and may be reversible after their withdrawal on a period that range from one to 36 weeks".

A few cases of parkinsonism have been reported secondary to amiodarone $\mathrm{e}^{12}$. The mechanism is unclear. However, experimental evidence and clinical observations suggest that basal ganglia mitochondrial impairment may contribute to this side effect. On the other hand, amiodarone has multichannel blocking effects, inhibiting transmembrane $\mathrm{Na}+$, IKs, IKur, IK1, and slow $\mathrm{Ca}(++)$ L-type calcium currents ${ }^{13}$. It can be toxic to almost every organ in the body including the central and peripheral systems, specially when taken at high doses for long periods of time ${ }^{12}$.

In summary, we consider that our patient presented with a PSP- like syndrome induced by amiodarone and flunarizine due to the rapid progression of classic manifestations of PSP which surprisingly disappeared after the drugs were withdrawn. It is believed that drugs can only anticipate symptoms of a preexistent but latent disease, and that it is very important follow these patients for a long period of time.

To our knowledge, this is the first published PSP-like syndrome secondary to amiodarone and flunarizine and the third case of PSP-like syndrome induced by drugs.

ACKNOWLEDGEMENTS - We thank Prof. Eric Sweet for his kind assistance in reviewing the manuscript.

\section{REFERENCES}

1. Litvan I. Progressive supranuclear palsy. In: Litvan I (Ed). Atypical parkinsonian disorders: clinical and research aspects. New Jersey: Humana Press, 2005:287-308.

2. Mattos JP. Diagnóstico diferencial. In: Meneses MS and Teive HAG (Eds). Doença de Parkinson. Rio de Janeiro: Guanabara Koogan, 2003:142-147.

3. Steele JC, Richardson JC, Olszewski J. Progressive supranuclear palsy. Arch Neurol 1964;10:333-359.

4. Weeks RA, Scaravilli F, Lees AJ, Carrol C, Husain M, Rudge P. Cerebral amyloid angiopathy and motor neurone disease presenting with a progressive supranuclear palsy-like syndrome. Mov Disord 2003;18:331-336.

5. Godeiro-Junior C, Inaoka RJ, Barbosa MR, Silva MRR, Aguiar PC, Barsottini O. Mutations in NPC1 in two Brazilian patients with NiemannPick disease type $\mathrm{C}$ and progressive supranuclear palsy-like presentation. Mov Disord 2006;21:2270-2272.

6. Campdelacreu J, Kumru H, Tolosa E, Valls-Solé J, Benabarre A. Progressive supranuclear palsy syndrome induced by clebopride. Mov Disord 2004;19:482-484.

7. Nicaretta DH, Rosso AL, Mattos JP. Discinesias induzidas por drogas. Rev Bras Neurol 2007;43:27-33.

8. Melo-Souza SE. Flunarizina, parkinsonismo e depressão. In: XI Congresso Brasileiro de Neurologia e IX Reunião da Liga Brasileira de Epilepsia. Goiânia: Resumos, 1984.

9. Terland O, Flatmark T. Drug-induced parkinsonism: cinarizine and flunarizine are potent uncouplers of the vacuolar H+-ATPase in catecholamine storage vesicles. Neuropharmacology 1999;38:879-882.

10. Wöber C, Brücke T, Wöber-Bingöl C, Asenbaum S, Wessely P, Podreka I. Dopamine D2 receptor blockade and antimigraine action of flunarizine. Cephalalgia 1994;14:235-240

11. Stephen PJ, Williamson J. Drug-induced parkinsonism in the elderly. Lancet 1984; 8411:1082-1083.

12. Dotti MT, Federico A. Amiodarone-induced parkinsonism: a case report and pathogenetic discussion. Mov Disord 1995;10:233-234.

13. Riera AR, Uchida AH, Ferreira C, et al. Relationship among amiodarone, new class III antiarrhythmics, miscellaneous agents and acquired long QT syndrome. Cardiol J 2008;15:209-219. 